\title{
Pieter Vermaas, Peter Kroes, Andrew Light and Steven A. Moore (eds): Philosophy and Design. From Engineering to Architecture
}

\author{
Springer, Dordrecht, 2008, 359 pp, ISBN 978-1-4020-6590-3
}

\author{
Marc de Vries
}

Published online: 12 August 2008

(C) The Author(s) 2008

Philosophy of technology is a discipline that has great relevance for technology education. That was why this journal in the past had some special issues on the philosophy of technology, and why new books in that field are reviewed regularly here. "Philosophy and Design", edited by Vermaas, Kroes, Light and Moore is such a publication. It offers a rich palette of essays and those who will read it, will get a good impression of the sort of themes and issues that are addressed now in this specific branch of philosophy. Twenty-six essays have been brought together in this volume, and that number makes it impossible to discuss them all in detail. In this review I will make an effort to show the variety of topics that are represented in the book. I hope our readers will feel themselves invited to read the book to get a fuller picture of what it has to offer.

Several of the contributions to this volume seem to have had their origin in a conference that was held in Delft, the Netherlands, in 2005. I remember that two of these contributions, namely those by Alfred Nordmann and by Paul Thomson, had served as keynote lectures at that event. The conference had been organized by the Society for Philosophy of Technology (SPT). Other conference papers found their way into SPT's scholarly journal, Techné. That journal is available on the web (via www.spt.org) and open for all to access. For technology educators it is a very useful (and free!) resource for reflections on the conceptual basis of technology education. SPT conferences are held every other year, alternating between the USA and Europe (the next conference will be in Enschede, the Netherlands, in 2009).

The fact that two consecutive SPT conferences in Europe are held in the Netherlands is not a coincidence. The Netherlands is an active country when it comes to philosophy of technology. Roughly speaking, the Delft and Eindhoven Universities of Technology take a more analytical approach, while the Twente University (located in Enschede) is primarily oriented towards Continental philosophers (although it must be emphasized that, apart from the current inappropriateness of the names the boundaries between the two streams in philosophy seem to get blurred). There is also a clear Delft influence in the book. Two of the editors (Vermaas and Kroes) are Delft staff members. Franssen, Houkes, Van Gorp and

M. de Vries $(\bowtie)$

Eindhoven University of Technology, Eindhoven, The Netherlands

e-mail: m.j.d.vries@tm.tue.nl 
Van de Poel, authors of three contributions, were also at Delft when the book was edited (Houkes later moved to Eindhoven and Van Gorp left when she acquired her Ph.D.). Twente is represented in two other contributions, by Brey and by Verbeek. Most other chapters are from Northern American authors. This reflects the current state of philosophy of technology: most of the research groups are in the USA, and in Europe it is particularly the Netherlands where we find larger philosophy of technology research programs.

The subtitle of the book points out that the editors wanted to offer reflections on a spectrum of design fields: "from engineering to architecture". In the introductory chapter, they show that this makes sense, because on the one hand there are differences between engineering and architecture as design fields, but on the other hand recent philosophical studies show that they also have important characteristics in common. The "dominant narrative", as they call it, emphasizes the differences between engineering and architecture. But there is also a "counter-narrative" in which the communalities are highlighted. These communalities feature in the design processes, design limits and in the ethical aspects of engineering and architecture. Having explained this, the editors show how these considerations have led to a structure for their book. In Part I there are nine essays on "engineering in the traditional "nuts-and-bolts" sense". Part II then contains the essays that focus on more recent and advanced technologies (e.g. nanotechnology and human enhancement technologies). Part III has the essays on architectural design. It is here in particular that we find the editors' intention most clearly addressed, as in the Part I and Part II essays comparisons between engineering and architecture are rarely made.

The first two chapters in Part I are typical for the (Delft) analytical approach in the philosophy of technology. This approach aims at carefully developing conceptual tools that help us understand the nature of technology, technological artifacts, technological knowledge, design, ethical dilemmas, etcetera. Proper reasoning and argumentation play a vital role in that effort. Although most non-philosophers perhaps are more interested in the 'big questions of life' sort of approach that we often find in the Continental approach, for education the analytical philosophy of technology is quite valuable. Teaching about something assumes a good conceptual understanding of it. Analytical philosophy helps to acquire that understanding. Current interests in the analytical philosophy of technology focus on such notions as function, design, and the relations between technical artifacts and agency, intentionality and normativity. The background of Franssen's chapter is the Delft "Dual Nature of Technical Artifact" program, in which technical artifacts are described in terms of their functional and structural (or physical) nature. Franssen challenges some of the ontological claims in this program. For education, the dual nature description is interesting because it seems to capture the very basics of what any technical artifact is in a very simple manner. That simplicity is very attractive for education. Rather than trying to make pupils and students understand all the details of the devices they see around them, we can start by providing a very basic understanding of what characterizes them in terms of these two natures. Houkes' idea of use plans that are always delivered with the artifact is of the same educational relevance. In his chapter he defends this concepts against some doubts that have been raised against it. Although a Heideggerian in many respects, Don Ihde, author of the next chapter, also has analytical interests, in particular when it comes to the way technical artifacts influence our perception of reality. The chapter in this book deals with the 'designer fallacy', which he describes as a sort of artifact-related version of the natural fallacy (i.e., deriving normative statements from descriptive statements). Ihde is a natural bridge to the next chapter, written by Brey, a Twente scholar (although it would have been even more 'natural' to have the chapter by Verbeek here, as his thesis was about Ihde). Brey's chapter is about another main stream in the philosophy of technology, 
namely the issue of whether or not evolutionary theories are adequate for describing technological developments. Currently, Houkes leads a research program about that in Eindhoven. Brey compares three evolutionary theories to see how they fit with technology.

Of course ethics of technology is well represented in the book. In this field the idea of 'value-sensitive design' is an emerging approach. Van Gorp and Van de Poel explore three cases studies (taken from Van Gorp's dissertation) to see how this works out in normal versus radical design (a notion taken from Vincenti, and although he is not mentioned, Constant developed this idea even before Vincenti). Verbeek in his chapter argues for an expansion of the ethics of technology by ascribing normativity, and with that also ethical notions, to artifacts. This is an interesting approach from an ethical points of view, although the ontological price that is to be paid for it seems to be rather high. Feng and Feenberg write about Feenberg's instrumentalization theory (in the line of Critical Theory). As Feenberg is one the best known philosophers of technology in the Continental tradition, this chapter is a valuable contribution to the book already for that reason. Naoe writes on risk, which is an important issue in the ethics of technology. It would have been nice if the book had a chapter by Sven Ove Hansson on this issue, but Naoe's chapter is certainly worth reading, as it puts the concept of risk, which is often treated as a neutral quantitative tool for assessing technological developments, in its proper cultural and human context. Although Thompson's chapter served as one of the keynote lectures at the mentioned SPT conference, I still have difficulties recognizing its value. He uses three concepts, alienability, rivalry and exclusion costs, to explain technological development, but it is not quite clear if something philosophically relevant happens with these existing concepts from institutional theory. But maybe for other readers the chapter serves as a welcome introduction to these concepts.

Part II has chapters on various concrete (and recent) technologies. Sullins writes about robotics, Rieder and Schäfer about software design, Nordmann about nanotechnology, Cerqui and Warwick about cyborgs, De Melo-Martín about genetic engineering, and Schmidt about human enhancement. The remaining chapters in Part II are again more general: Miettinen's and Kroh's chapters are about systems design, and the chapters by Neeley and Luegenbiehl and Cook deal with responsibility. The philosophical quality of the chapters varies. Some chapters offer a sound description of technological developments but do not offer much in terms of philosophical reflections on those. Other chapters are not very concrete in terms of systems or artifacts, but have a stronger focus on philosophy. Part III is the architecture part of the book. Here we find several interesting chapters. It is difficult anyway to find good philosophical articles on architecture, as architects do a lot of good thinking but do not always write about it. In the book we find comparisons between architectural design and engineering design. Davis' chapter shows how in particular recent developments in the role of architects have enhanced the communalities with the engineer's role. One chapter I found particularly interesting was that by Moore and Webber in which they use three different design presentations for the same building to show how a conventional rendering, an abstract rendering and an explanatory rendering address different target groups by including different values of a building. In their terms: there is a politics of representation, that is convincingly presented in this chapter. Cavanagh's chapter takes up again the dual nature discussion, which was already present in Franssen's chapter (in Part I) by challenging the applicability of this concept to architectural artifacts. Pitt discusses design criteria in architecture from a pragmatist point of view. Hanks' and Parsons' chapters are at the level of city planning and thus nicely complement the other chapters in this Part of the book. 
Although this book was written by philosophers, I think it is well accessible to nonphilosophers. Most authors have a background in natural sciences and/or engineering, and because of that know how to write in such a way that non-philosophers do not get lost in philosophical jargon. Therefore I warmly recommend the book to technology educators, in particular those that work in research or teacher education and can use it to enrich teacher education programs with insights from the philosophy of technology. For those who want to see the broader context of philosophy of technology, as a background from which the content of this book can be even better understood, I refer to my own book Teaching About Technology, that came out with the same publisher some years ago.

Acknowledgments Open Access This article is distributed under the terms of the Creative Commons Attribution Noncommercial License which permits any noncommercial use, distribution, and reproduction in any medium, provided the original author(s) and source are credited. 